\title{
A Simple and Rapid Method to Assess the Quality of River Water: Correlation Between Electrical Conductivity and Fecal Coliform Density in Hyogo Prefecture, Japan
}

Hanna Horiguchi ( $\nabla$ hannahoriguchi@gmail.com )

Osaka University: Osaka Daigaku https://orcid.org/0000-0001-7835-0703

Katsumi Shigemura

Kobe University: Kobe Daigaku

Koichi Kitagawa

Kobe University: Kobe Daigaku

Madoka Kitakawa

Kobe University: Kobe Daigaku

Minato Nakazawa

Kobe University: Kobe Daigaku

Tatsuhiko Noyori

Toga River Conservancy

Motomu Inoue

Kobe University: Kobe Daigaku

Michika Moriwaki

Kobe University: Kobe Daigaku

Reo Onishi

Kobe University: Kobe Daigaku

Chisato Yoshimura

Kobe University: Kobe Daigaku

Mayumi Kobayashi

Kobe University: Kobe Daigaku

Toshinobu Suzaki

Kobe University: Kobe Daigaku

\section{Research Article}

Keywords: Urban river environment, Electrical conductivity, Fecal coliform density, Water pollution, Water safety, Screening method 
Posted Date: January 31st, 2022

DOI: https://doi.org/10.21203/rs.3.rs-1236780/v1

License: (c) (i) This work is licensed under a Creative Commons Attribution 4.0 International License. Read Full License 


\section{Abstract}

This is a report regarding the development of a simple survey method for monitoring water pollution in the Toga River in Kobe City, Japan. This river is popular with local citizens as a water park, and especially in the summer, various activities are introduced to encourage children to play in the river. However, in recent years, contamination by fecal coliforms, probably caused by the accidental influx of domestic wastewater, often limits children from playing in the water. From May to October 2019, water samples were collected from five locations in the Toga River and the concentration of fecal coliforms was measured, along with the electrical conductivity and the chloride ion concentration of the river water, to establish a method for estimating the fecal coliform density (FCD) as a quicker alternative to a culture test. By comparing these parameters with the actual density of fecal coliforms, a high correlation was found between the electrical conductivity and FCD. On the other hand, there was almost no correlation between FCD and the chloride concentration. Receiver operating characteristic (ROC) analysis was used to evaluate the method that uses the electrical conductivity as an estimating parameter. The area under the curve (AUC) was used to determine the performance of the ROC curve algorithm. The calculated AUC value stayed high, above 0.95 , over a wide range of threshold values of FCD, suggesting that this rapid method is appropriate for assessing the quantity of contaminating fecal coliforms in the range of 300$2,000 / 100 \mathrm{~mL}$.

\section{Introduction}

Rivers in urban areas play various and important roles including flood control, a reservoir to be used in extinguishing fires and a space for recreational and commercial use by residents. During summer, people, especially children, enjoy swimming, fishing, or camping in and near bodies of water and rivers in Japan. Therefore, in order to ensure water hygiene, the fecal coliforms density (FCD), oil film, chemical oxygen demand (COD), and transparency of the water have been measured every year in May and June since 1973 by the Ministry of the Environment and local governments (https://www.env.go.jp/en/water/wq/wbcbbeach.html).

Among these factors, FCD is an important factor in the safety criteria of water; fecal coliforms are rodshaped, gram-negative, non-sporulating bacteria and are used as indicator of sewage and feces contamination and the possible presence of pathogenic microorganisms, although they are generally not harmful in themselves (Bordalo and Savva-Bordalo, 2007; Pandey et al., 2009). The permitted FCD levels in the water for recreational use is $1,000 / 100 \mathrm{~mL}$ or less with a density of $100 / 100 \mathrm{~mL}$ or less required for the class 'proper' in the criteria of Ministry of the Environment of Japan. However, the concentration of fecal coliforms in river water varies depending on the season, weather, or human activities, while standard methods used to analyze bacteria in the water is laborious, time consuming and expensive. Therefore, it is desirable to develop easier and more rapid methods for assessing the quality of river water to enable frequent and multiple measurements (Hughes, 2003; Brouwer, 1985). 
In this study, we measured the electrical conductivity and the chloride ion concentration of an urban river in Hyogo prefecture and compared the data obtained to the FCD for six months aiming to use these parameters as an alternative or pre-examination and complementary measure for evaluating the water quality. Furthermore, as a case study we investigated whether it is possible through these analyses to identify the region in the city that might be responsible for a higher level of pollution in this urban river.

\section{Material And Methods}

\subsection{Location of Toga River and sampling points}

The Toga River (Toga-gawa) is one of the main rivers that flow through the city of Kobe, Hyogo prefecture, Japan. The river originates on the southern slopes of the Rokko Mountains and has a total length of about $10 \mathrm{~km}$ with two main tributaries (Fig. 1). Downstream, the river runs through residential areas, and in summer children play in the water (site A in Fig. 1).

The water samples were collected on May 9, June 4, July 9, August 8, September 4 and October 4, 2019, at between $10 \mathrm{~h} 30$ and $12 \mathrm{~h} 30$. The sampling points were limited to the main stream and effluent 2 sites only, as shown in Fig. 1, because the preliminary survey ruled out the possibility of effluent 1 as a source of water pollution. The samples were collected in $15 \mathrm{~mL}$ plastic tubes, kept at $4^{\circ} \mathrm{C}$, and electrical conductivity and chloride ion concentration were measured within 1-2 days. For FCD measurements, water was collected in $50 \mathrm{~mL}$ plastic tubes and analyzed immediately after collection.

\subsection{Measurements}

\subsubsection{Electrical conductivity and chloride ion concentration}

The electrical conductivity and chloride ion concentration of the sample water were measured with a conductivity meter (LAQUAtwin-EC-33, HORIBA, Kyoto, Japan) and a digital pack test ( $\mathrm{Cl}^{-}$) (DPM2-Cl, Kyoritsu Chemical-Check Lab., Corp., Tokyo, Japan), respectively, according to the manufacturers' instructions. The conductivity meter was carefully calibrated using a standard solution each time before a measurement.

\subsubsection{Fecal coliforms density (FCD)}

The number of fecal coliforms in the sampled water were measured by the membrane filter method (Dufour et al., 1981) with some modifications: a $50 \mathrm{~mL}$ sample of river water was passed through a membrane filter (Millipore HA $0.45 \mu \mathrm{m}$ ) using an aspirator. The filter was placed on a McConkey agar plate containing lactose $(1 \% \mathrm{w} / \mathrm{v})$ and incubated at $44.5^{\circ} \mathrm{C}$ for 24 hours. Bile salt on the plate inhibits the growth of most gram-positive bacteria, and the elevated temperature disturbs the non-fecal bacteria and suppresses their growth. Differentiation between enteric microorganisms is achieved by the combination of a neutral red indicator and lactose as the coliforms ferment lactose and produce acid that changes the neutral red $\mathrm{pH}$ indicator from colorless to red. Acid production is also responsible for the formation of bile salt precipitation. As a result, fecal coliforms form red colonies surrounded by a zone of bile salt 
precipitation. When the number of colonies on a filter exceed one thousand, a reduced volume of sample ideal for obtaining 10 200 colonies per plate was spread out and bacteria was grown as above. The red colonies were counted and recorded as the number of coliform bacteria. The density of fecal coliform bacteria in the water was calculated from the average of duplicate samples for each sampling spot.

\subsubsection{Estimation of FCD}

To develop a simple method for estimating the density of fecal coliform bacteria, we evaluated the following three estimation models. The first model (model A) uses the electrical conductivity as the independent variable to fit the logarithm of FCD in a simple linear regression and provides the formula as an index for estimating FCD. In the second model (model B), the chloride ion concentration is used in place of the electrical conductivity. The third (model $\mathrm{C}$ ) is a multiple linear regression model where both the electrical conductivity and the chloride ion concentration are independent variables in the equation that estimates the logarithm of FCD as a response variable. Receiver operating characteristic (ROC) analysis, which is a well-known strategy for assessing the fit of models to the actual measurement results, was used to evaluate these three estimation methods (He et al., 2018). The Area Under the Curve (AUC) method was used to determine the performance of the ROC curve algorithm (He et al., 2018).

\section{Results}

In recent years, occasional contamination with fecal coliforms has been observed in Toga River. Contamination was found mainly at the main stream and effluent 2 sampling points. As the purpose of this study is to develop a method for easily detecting water pollution in rivers, samples were taken at several points and their chemical characteristics were measured to investigate their connection to the contamination of fecal bacteria.

\subsection{Relationship between fecal coliform density (FCD) and river water properties.}

A total of 55 water samples were collected at five points in the Toga River water system (Fig. 1) between May and October 2019 , and the $F C D$, electrical conductivity at $25^{\circ} \mathrm{C}$, and chloride ion concentration were measured. As shown in Fig. 2A, electrical conductivity and FCD clearly showed a positive correlation with a determination coefficient of $R^{2}=0.547$. While little correlation was observed between chloride concentration and FCD with $\mathrm{R}^{2}=0.051$ (Fig. 2B). Multiple regression analyses were performed to obtain the best estimation by using both electrical conductivity and chloride ion concentration, and the following formula was obtained by using the ordinary least squares :

$\log _{10}(B a c)=0.0314 \times C h+0.0256 \times C o-1.97$, where $B a c$ is the estimated coliforms density (cells $/ 100 \mathrm{~mL}$ ), $C h$ is the chloride ion concentration $(\mathrm{mg} / \mathrm{L})$, and $C o$ is the electrical conductivity of the sample water $(\mu \mathrm{S} / \mathrm{cm})$. Fig. $2 \mathrm{C}$ shows the correlation between the estimated values of FCD by the above equation and the actual values of bacterial density, showing a slightly better correlation as compared with Fig. 2A. 


\subsection{Evaluation of mathematical models for estimating FCD}

Next, receiver operating characteristic (ROC) analysis was performed to evaluate the estimation models shown in Fig. 2. For each model, the ROC curve was plotted setting the threshold value of FCD at 1000 cells/100 mL, the limit for safe sea bathing within the regulation by the Ministry of the Environment of Japan. The model performance was evaluated by calculating the area under the curve (AUC), which indicated that Models A and C perform better than does Model B (Fig. 3). For each model, AUC values were determined and plotted against different threshold values of FCD. As shown in Fig. 4, Models A and $\mathrm{C}$ maintained high AUC values above 0.95 over a wide range of threshold values, suggesting that these models can be used to assess FCD in the range between 300 and 2000/100 mL. Furthermore, addition of the chloride ion concentration as an independent variable was found to add no benefit to the estimation of coliform bacterial density. Therefore, it was concluded that electrical conductivity alone is sufficient for the estimation.

\subsection{Estimation of coliform bacterial density in Toga River}

According to the above investigation, seasonal changes in FCD were estimated from the electrical conductivity of the water samples (Model A) as shown in Fig. 5. The results indicated that the pollution level of Site A was closely related to Site $C$ on the Affluent 2 site of the Toga river (Fig. 1), suggesting that the source of the water pollution may have been somewhere along this affluent zone. It was also shown that no significant river pollution was seen in July and September. This may indicate that the sewage from the source was discharged intermittently.

\section{Discussion}

Water quality regulations for swimming and recreation are enforced around the world to protect humans and the environment from hazardous pollution levels (Kirschner et al., 2009; Nevers et al., 2014; Reder et al., 2015). Although the methods used to quantify microbial water quality vary, common procedures include culturing of fecal microorganisms (e.g., Escherichia coli and enterococci) using indicator media. However, these culture-based methods require time and labor before a result is obtained.

This study investigated whether FCD could be estimated from physical or chemical parameters of river water which are easy and quick to measure. One parameter is electrical conductivity, and another is chloride ion concentration. Electrical conductivity is considered one of the predictive parameters for water hygiene, but its utility appears to vary from region to region. Guzman-Otazo et al. (2019) showed that electrical conductivity was positively associated with DNA concentration, number of gapA-positive bacteria and pathogenic E. coli in the Choqueyapu River in La Paz, Bolivia. In contrast, conductivity did not show a significant correlation with E. coli or total coliforms in the Red River basin of North Vietnam (Nguyen et al., 2016) and in the groundwater within the gold mining environment of Ghana (Armah, 2014). Chloride ion concentration is also considered as a physicochemical indicator of water pollution caused by organic waste from animals or industrial origins (Bhadra et al., 2003). David and Haggard 
(2011) showed that fecal bacterial concentrations were significantly correlated with dissolved chloride ion concentrations in the Illinois River in USA. In contrast, it was argued that chloride concentrations were unrelated to fecal contamination in the Mfoundi River Basin of Yaoundé, Cameroon (Djuikom et al., 2009). Our study also showed no significant correlation between chloride ion concentration and FCD in the Toga River, Japan. As described by Howard et al. (2004), chloride ions may be minimal as indicators of water pollution, because they are often found in water originating from sources other than that containing fecal matter. Chloride ions found in urban rivers may be due to various human activities such as road salt removers, fabric softeners and discharge of sewage containing food waste (Hunt et al., 2012). Kobe City's location near the coast may also affect the seasonal or temporal change of chloride ion concentration. On the other hand, our data showed that electrical conductivity was an excellent parameter for estimating FCD in river water indicating its utility as a convenient and time-saving screening tool. Urban rivers flow through residential areas where agriculture, animal husbandry and wildlife are not potential sources of water pollution, therefore, the increase of conductivity will mostly reflect contamination from sewage and household drainage. Furthermore, in the case of the Toga River, possible causes of increased conductivity such as industrial effluent and groundwater contamination are rare, which seems to make electrical conductivity a reliable parameter.

The results of our study have revealed potential sources of fecal coliform contamination in the Toga River. As shown in Fig. 5, high FCDs were estimated at sites A and C, but were lower at upstream sites D and $E$. Site $C$ showed the highest values at each sampling time, suggesting that affluent 2 is at least partly responsible for the pollution levels. The lower values at site B are probably due to the dilution of affluent 2 water in the main stream of the Toga River. Affluent 1 merges with the mainstream between sites $A$ and $B$, but our previous investigation confirmed that this affluent zone is adequately isolated from the residential area and no significant fecal coliform pollution was observed at any time (data not shown). Therefore, it is unlikely that the inflow of contaminated water from affluent 1 caused high values at site A. Further study and detailed investigations are necessary to clarify the reason for the observation at site $A$.

Finally, Fig. 6 shows the correlation between the FCD measured at site $C$ and the value estimated from the electrical conductivity of the same sample water. There is a good correlation between the measured and estimated values, indicating that electrical conductivity is a good indicator of fecal contamination. The FCD varied greatly depending on the month of measurement, indicating that fecal contamination occurred intermittently at the affluent 2 site. In July and September, the FCD was below the value set by the Ministry of the Environment of Japan as being suitable for swimming. The point where pollution occurs and the frequency of discharge of polluted water are still unknown, but in the future, an attempt will be made to identify the location of the source using electrical conductivity as an index.

\section{Conclusions}

This study showed that the electrical conductivity of a river in a Japanese city was significantly correlated with the density of fecal coliforms that were probably introduced from domestic wastewater. 
Measuring electrical conductivity is inexpensive, easy and quick. Therefore, this method is useful as a preliminary test for the usually costly and time-consuming test of fecal coliforms density, and as a means for identifying the location of river pollution caused by accidental inflow of domestic wastewater.

\section{Declarations}

\section{Ethical Approval}

Not applicable

\section{Consent to Participate}

Not applicable

\section{Consent to Publish}

Not applicable

\section{Author Contributions}

TS and MNcontributed to the study conception and design. Material preparation, data collection and analysis were performed by $\mathrm{KK}, \mathrm{MK}, \mathrm{HH}, \mathrm{MN}, \mathrm{TN}, \mathrm{MI}, \mathrm{RO}$ and $\mathrm{T} \mathrm{S}$. $\mathrm{HH}$ wrote the first draft of the manuscript. All authors commented on previous version of the manuscript and approved the final manuscript.

\section{Funding}

This work was partially supported by a commissioned project for JSPS 267 KAKENHI (grant number: 19K09670) to KS.

\section{Competing Interest}

The authors declare that they have no known competing financial interests or personal relationships that could have influenced the work reported in this paper.

\section{Availability of data and materials}

The data that support the findings of this study are available from the corresponding authorupon reasonable request.

\section{Acknowledgements}

The authors would like to thank all members of Toga River Conservancy, city hall workers, residents for assistance with the experiments and Professor Dr. Masato Fujisawa for collaboration and advice.

\section{References}


1. Armah FA. Relationship between coliform bacteria and water chemistry in groundwater within gold mining environments in Ghana. Water Qual Expo Health 2014;5(4):183-195.

2. Bhadra B, Mukherjee S, Chakraborty R, Nanda AK. Physico-chemical and bacteriological investigation on the River Torsa of North Bengal. J Environ Biol 2003;24(2):125-133.

3. Bordalo AA, Savva-Bordalo J. The quest for safe drinking water: An example from Guinea-Bissau (West Africa). Water Res 2007;41(13):2978-2986. doi:10.1016/j.watres.2007.03.021.

4. Brouwer CJ, Food and Agriculture Organization of the United Nations. 8.4 Microbiological methods in Scheme Irrigation water Needs and Supply: page 150, A Manual. Food \& Agriculture Org.; 1985.

5. David MM, Haggard BE. Development of regression-based models to predict fecal bacteria numbers at select sites within the Illinois River watershed, Arkansas and Oklahoma, USA. Water Air Soil Pollut 2011;215(1-4):525-547. https://doi.org/10.1007/s11270-010-0497-7.

6. Djuikom E, Jugnia LB, Nola M, Foto S, Sikati V. Physicochemical water quality of the Mfoundi River watershed at Yaoundé, Cameroon, and its relevance to the distribution of bacterial indicators of faecal contamination. Water Sci Technol 2009;60(11):2841-2849. doi:10.2166/wst.2009.702.

7. Dufour AP, Strickland ER, Cabelli VJ. Membrane filter method for enumerating Escherichia coli. Appl Environ Microbiol 1981;41(5):1152-1158.

8. Fernández-Molina MC, Álvarez A, Espigares M. Presence of hepatitis A virus in water and its relationship with indicators of fecal contamination. Water Air Soil Pollut 2004;159(1):197-208. https://doi.org/10.1023/B:WATE.0000049176.30748.0b.

9. Guzman-Otazo J, Gonzales-Siles L, Poma V, Bengtsson-Palme J, Thorell K, Flach CF, Iñiguez V, Sjöling Å. Diarrheal bacterial pathogens and multi-resistant enterobacteria in the Choqueyapu River in la Paz, Bolivia. PLOS ONE 2019 January 14;14(1):e0210735.

10. He R, Chen $Y$, Huang Q et al. Evaluation of ocean-atmospheric indices as predictors for summer streamflow of the Yangtze River based on ROC analysis. Stoch Environ Res Risk Assess 2018;32(7):1903-1918. https://doi.org/10.1007/s00477-018-1551-z.

11. Howard I, Espigares E, Lardelli P, Martín JL, Espigares M. Evaluation of microbiological and physicochemical indicators for wastewater treatment. Environ Toxicol 2004;19(3):241-249. doi: 10.1002/tox.20016.

12. Hughes KA. Influence of seasonal environmental variables on the distribution of presumptive fecal coliforms around an Antarctic Research Station. Appl Environ Microbiol 2003;69(8):4884-4891. doi:10.1128/AEM.69.8.4884-4891.2003.

13. Hunt M, Elizabeth Herron and Linda Green. Chlorides in Fresh Water. URI WATERSHED WATCH. March 4, 2012.

14. Kirschner AKT, Kavka GG, Velimirov B, Mach RL, Sommer R, Farnleitner AH. Microbiological water quality along the Danube River: Integrating data from two whole-river surveys and a transnational monitoring network. Water Res 2009;43(15):3673-3684.

15. Nevers MB, Byappanahalli MN, Edge TA, Whitman RL. Beach science in the Great Lakes. J Gr Lakes Res 2014;40(1):1-14. doi: 10.1016/j.jglr.2013.12.011. 
16. Nguyen HT, Le QT, Garnier J, Janeau JL, Rochelle-Newall E. Seasonal variability of faecal indicator bacteria numbers and die-off rates in the Red River basin, North Viet Nam. Sci. Rep.:21644. Sci Rep 2016;6 Feb 12;6:21644. doi: 10.1038/srep21644. PMID: 26869451; PMCID: PMC4751496.

17. Pandey S, Singh S, Pani S, Malhosia A. Water quality and pollution status of Lararpur reservoir with special reference to bacterial contamination. Nat Prec August 25, 2009;1-1. doi:10.1038/npre.2009.3645.1.

18. Raith MR, Ebentier DL, Cao Y, Griffith JF, Weisberg SB. Factors affecting the relationship between quantitative polymerase chain reaction (qPCR) and culture-based enumeration of Enterococcus in environmental waters. J Appl Microbiol 2014 March;116(3):737-746. doi: 10.1111/jam.12383.

19. Reder K, Flörke M, Alcamo J. Modeling historical fecal coliform loadings to large European rivers and resulting in-stream concentrations. Environ Modell Softw2015;63:251-263. doi: 10.1016/j.envsoft.2014.10.001.

\section{Figures}

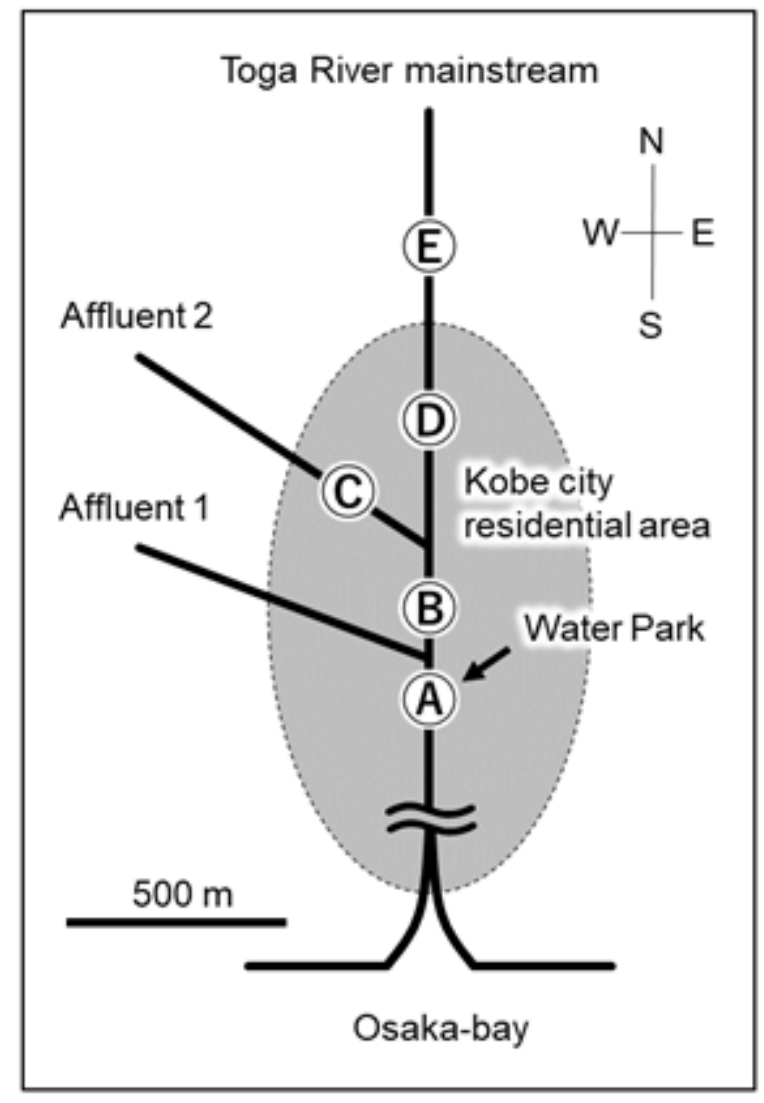

\section{Figure 1}

Schematic diagram of the Toga River system and the sampling points. The Toga River passes through the Kobe City from north to south and has two main affluent sites. Site A has a water park, which is designed in a way where children canplay in the river in summer. 

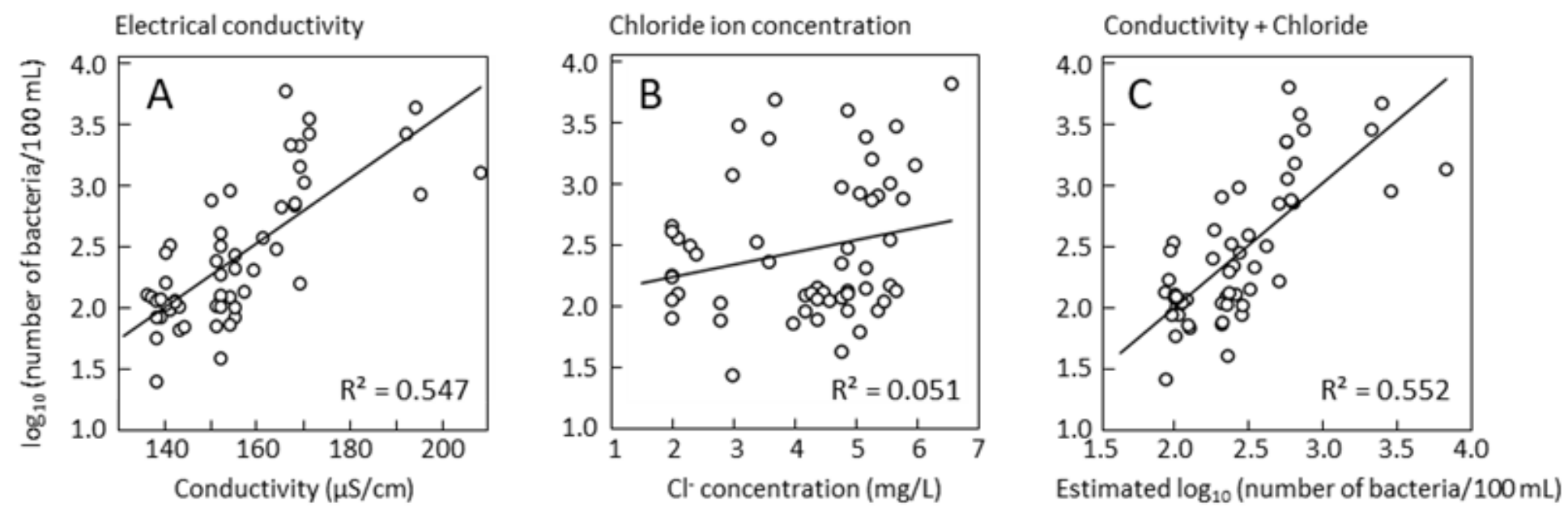

Figure 2

Relationship between the density of fecal coliform density and river water properties. A total of 55 water samples were collected from five points in the Toga River water system, and the FCD, electrical conductivity at $25^{\circ} \mathrm{C}$, and chloride ion concentration were measured. The relationship between FCD and electrical conductivity (A), and between FCD and chloride ion concentration (B) was depicted. (C) The relationship between the estimated FCD using the equation ${ }^{1)}$ obtained by multiple regression analysis and actual measured FCD. Each graph shows the $r^{2}$ value.

1) equation: $\log _{10}(B a c)=0.0314 \times C h+0.0256 \times C o-1.97$, where $B a c$ is the estimated coliform density (cells/ $100 \mathrm{~mL}$ ), $C h$ is the chloride ion concentration $(\mathrm{mg} / \mathrm{L})$, and Co is the electrical conductivity of the sample water $(\mu \mathrm{S} / \mathrm{cm})$.

Model A:

Electrical conductivity

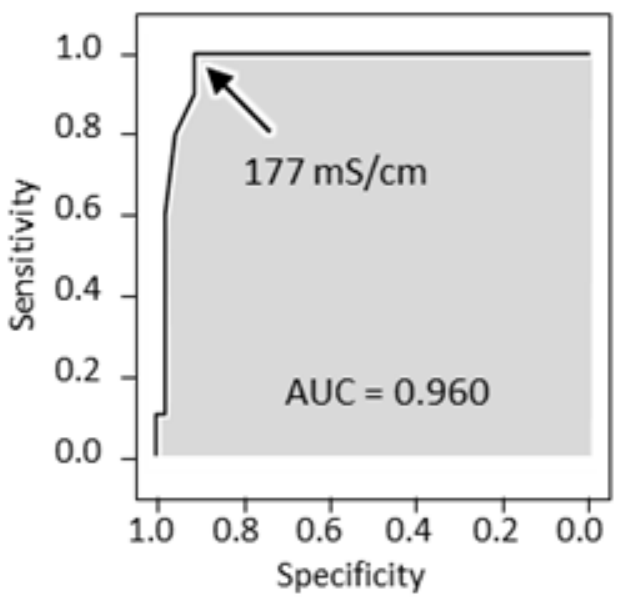

Model B:

Chloride ion concentration

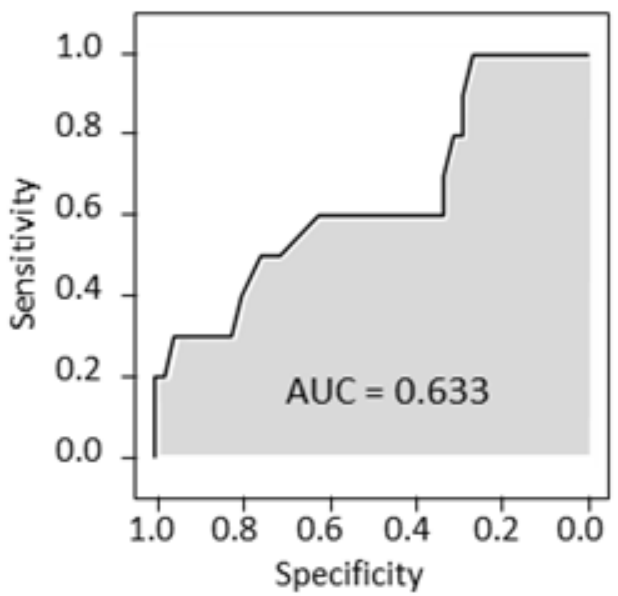

Model C:

Conductivity + Chloride

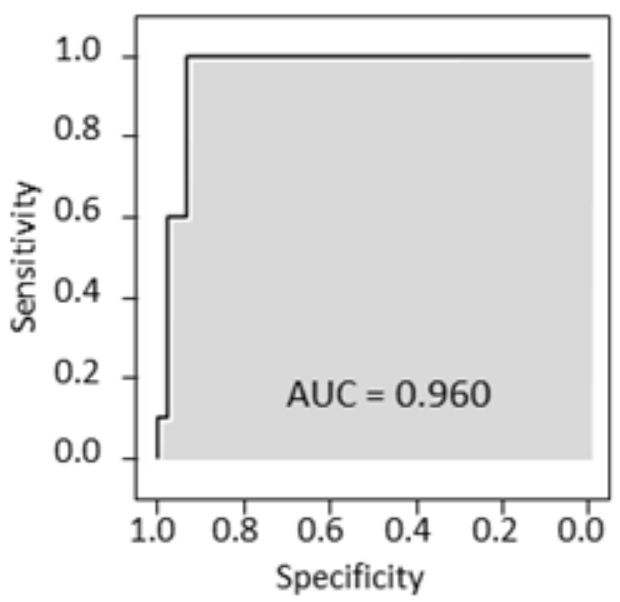

Figure 3

ROC curves determined by three different statistical models to estimate the density of fecal coliform bacteria in water. The threshold value of the FCD was set at 1000/100 mL. AUC values were calculated 
directly from the graphs. Left (Model A): linear regression model with electrical conductivity as a single parameter. Middle (Model B): linear regression model with chloride ion concentration as a single parameter. Right (Model C): multiple regression model with electrical conductivity and chloride ion concentration as predictor variables using the equation shown in Fig. $2 \mathrm{C}$. Comparison of the AUC values shows that Models $A$ and $C$ are better than $B$. In model $A$, the cut-off value was $177 \mathrm{mS} / \mathrm{cm}$.

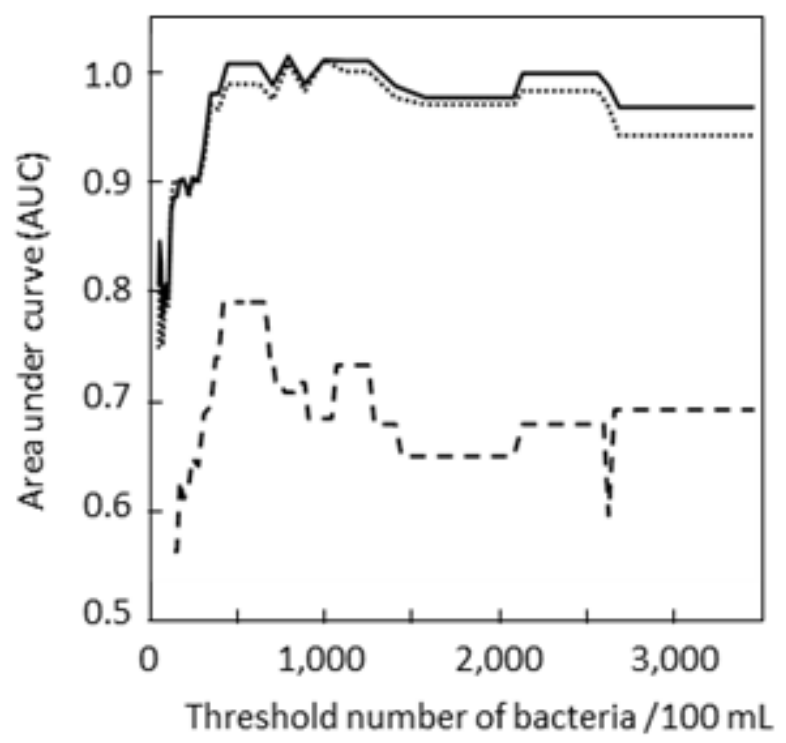

\section{Figure 4}

The area under curves (AUC) are calculated for three different statistical models for estimating the density of fecal coliform bacteria in water. For each model, ROC curves were plotted against different threshold values of the FCD between 300 and 2000 in $100 \mathrm{~mL}$. AUC values were calculated directly from ROC curves. Solid line: linear regression model with electrical conductivity as a single parameter (model A). Broken line: linear regression model with chloride ion concentration as a single parameter (model B). Dotted line: multiple regression model with electrical conductivity and chloride ion concentration as predictor variables (model C). 


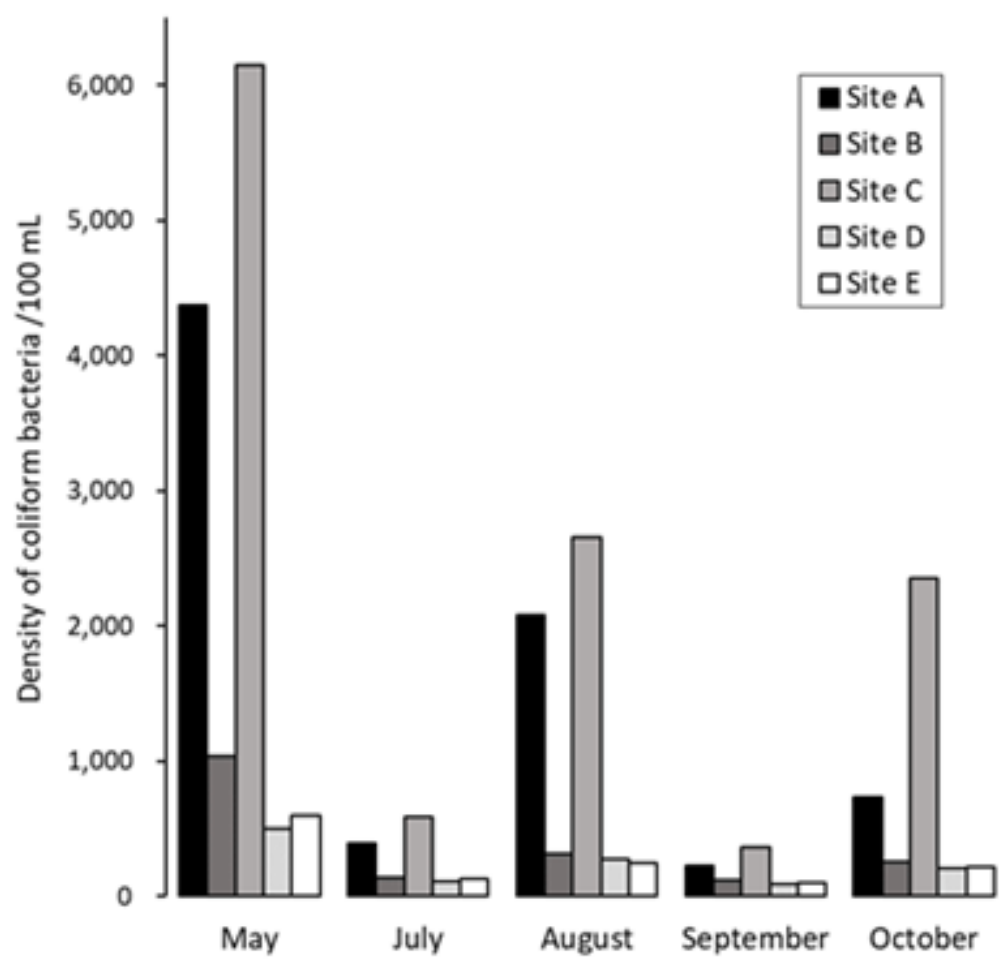

Figure 5

Seasonal changes in the density of fecal coliform bacteria at different sampling points. The FCD was estimated from the electrical conductivity of the water samples. Very little river pollution was observed in July and September, which indicates that the discharge of sewage from the pollution source occurred intermittently.

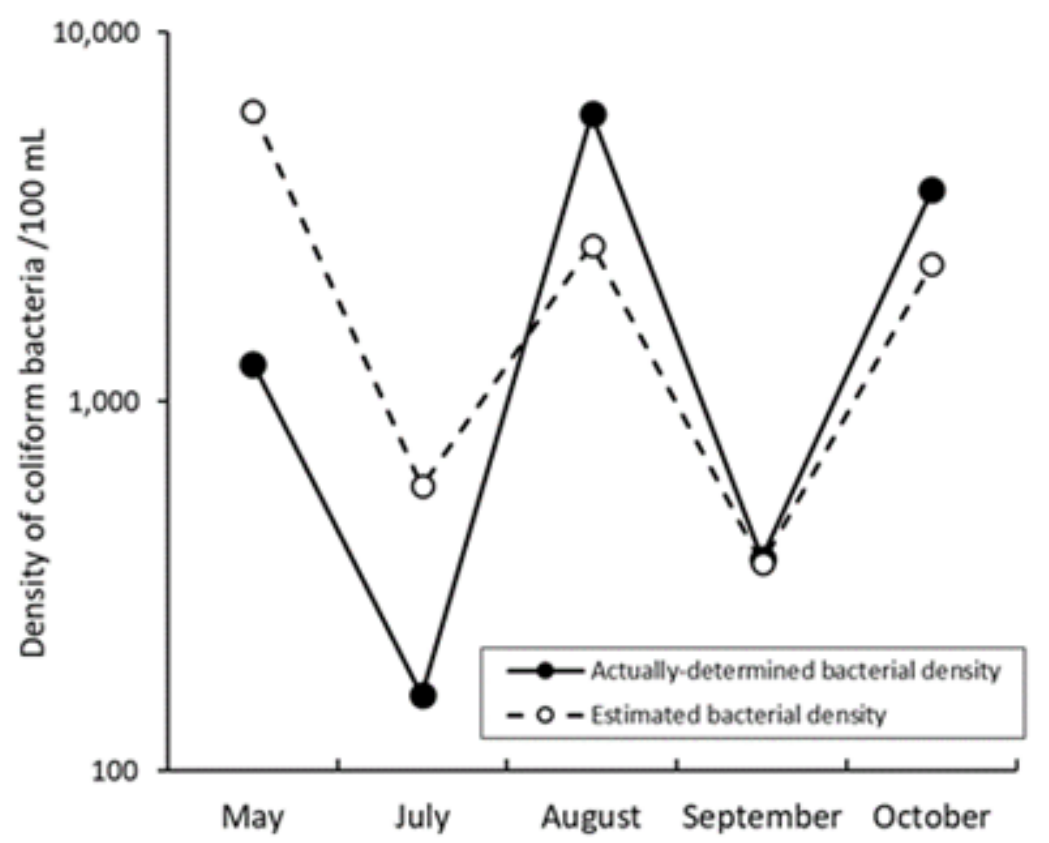

Figure 6 
Correlation over time between the density of fecal coliform measured and the value estimated from the electrical conductivity at site $\mathrm{C}$. The measured and estimated values show a good correlation. 